\title{
HUBUNGAN STATUS GIZI DENGAN INDEKS PRESTASI KUMULATIF MAHASISWI JURUSAN D III KEBIDANAN TINGKAT II POLTEKKES KEMENKES SORONG TAHUN 2014
}

\author{
Anjar Briliannita ${ }^{1}$, Adriana Pagayang ${ }^{2}$ \\ ${ }^{1,2}$ Jurusan Gizi Politeknik Kesehatan Kementerian Kesehatan Sorong, Papua Barat \\ Email : abriliannita@gmail.com
}

ABSTRACT

Pregnant of women need intake in fulfilling nutrition for the growth and development of the fetus they contain. From the data obtained shows that there are still many pregnant women who ignore and do not pay attention to their nutritional fulfillment during pregnancy. Determine the relationship between nutrient intake and nutritional status in pregnant women at the Remu Puskesmas in Sorong City.

The design of this study used a description method, with a cross sectional design. Samples are pregnant women, as many as 35 people, taken by random sampling. Data analysis using chi square count compared with chi square table.

Based on the results of the Chi Square test, the value of $x^{2}$ count (3.922) <x2 table (5.991) means that there is no relationship between nutritional status and cumulative achevment index in the second level DIII midwifery education of the Ministry of Health in Sorong. This is because the activity factor is too dense so that it influences the concentration of learning and the lack of active participation in the lecture process so that the subjects are largely left behind. It is recommended that respondents further improve their nutritional status.

Keywords: Nutrition Status, Cumulative Achievment Index

\begin{abstract}
ABSTRAK
Status gizi mempengaruhi tingkat kecerdasan dan kemampuan dalam menangkap pelajaran di sekolah, seseorang memiliki status gizi baik akan mempunyai daya tangkap yang lebih baik, sebaliknya jika memiliki status gizi kurang atau lebih akan berdampak pada kecerdasan sehingga kurang optimal dalam menangkap pelajaran di sekolah dan prestasi belajar menjadi kurang baik. Tujuan penelitian ini adalah untuk mengetahui hubungan antara status gizi dengan IPK Mahasiswi DIII Kebidanan Poltekkes Kemenkes Sorong Tahun 2014.

Desain penelitian yang digunakan adalah observasional analitik yaitu penelitian yang dilakukan untuk menghubungkan antara variabel independent dan variabel dependent dengan pendekatan "cross sectional" yaitu penelitian pada beberapa populasi yang diamati pada waktu yang sama. Jumlah populasi sebanyak 106 dan sampel yang didapatkan sebanyak 71. Teknik yang digunakan dalam pengambilan sampel adalah Simple Random Sampling.

Berdasarkan hasil uji Chi Square diperoleh nilai $x^{2}$ hitung $(3,922)<x^{2}$ tabel $(5,991)$ yang berarti tidak adanya hubungan antara status gizi dengan IPK mahasiswi DIII kebidanan tingkat II Poltekkes Kemenkes Sorong. Hal ini dikarenakan faktor aktivitas yang terlalu padat sehingga berpengaruh terhadap konsentrasi belajar dan kurang aktifnya mengikuti proses perkuliahan sehingga mata kuliah sebagian besar tertinggal. Disarankan kepada responden lebih meningkatkan status gizinya.
\end{abstract}

Kata Kunci : Status Gizi, Indeks Prestasi Kumulatif

\section{PENDAHULUAN}

World Health Organization (WHO) menyatakan bahwa gizi adalah pilar utama dari kesehatan dan kesejahteraan sepanjang siklus kehidupan (Soekirman, 2002)

Kecerdasan kognitif seseorang erat kaitannya dengan status gizi seseorang (Hardinsyah, 2007). Gizi kurang dapat mengganggu motivasi anak, kemampuannya untuk berkonsentrasi, dan kesanggupannya untuk belajar. Status gizi akan mempengaruhi tingkat kecerdasan seseorang dan kemampuan seseorang dalam menangkap pelajaran di sekolah, sehingga seseorang yang memiliki status gizi baik akan memiliki daya tangkap yang lebih baik dan dapat memperoleh prestasi yang baik pula di sekolahnya. Sebaliknya jika 
seseorang memiliki status gizi yang kurang atau lebih akan berdampak pada kecerdasan sehingga kurang optimal dan prestasi belajar kurang baik.

Data Riskesdas menyajikan prevalensi penduduk umur dewasa kurus, gizi lebih dan obesitas menurut IMT/U di masing masing provinsi. Prevalensi penduduk dewasa kurus $8,7 \%$ dan untuk provinsi Papua Barat lebih besar dari prevalensi nasional yaitu sebesar 40\% (Riskesdas 2013).

Berdasarkan penelitian yang dilakukan oleh (Khairunisa, 2011) pada mahasiswi Akbid Gema Bekasi sebanyak 83 orang menunjukkan bahwa terdapat hubungan antara status gizi dengan indeks prestasi kumulatif mahasiswa akademi kebidanan gema nusantara bekasi tahun 2011 ( Khairunisa, 2011).

Penelitian yang dilakukan oleh Kapisa, (2013) pada mahasiswa/i jurusan keperawatan tingkat IA sebanyak 62 mahasiswa. Penelitian dari 62 mahasiswa tersebut terdapat mahasiswa yang memiliki status gizi kurang sebanyak 5 orang $(8,06 \%)$, status gizi baik 50 orang $(80,6 \%)$, dan gizi lebih sebanyak 7 orang $(11,2 \%)$. Sedangkan yang memiliki nilai baik ada 22 orang $(35,4 \%)$ dan yang memiliki nilai cukup sebanyak 40 orang (64,5\%). Berdasarkan analisis bivariat status gizi dan prestasi akademik terdapat 20 mahasiswa $(32,2 \%)$ yang memiliki status gizi baik dan memperoleh prestasi yang baik pula (Kapisa, 2013).

Berdasarkan latar belakang tersebut, penulis tertarik untuk meneliti hubungan status gizi dengan indeks prestasi kumulatif (IPK) Mahasiswi jurusan D III Kebidanan tingkat II Poltekkes Kemenkes Sorong tahun 2014.

\section{SUBJEK DAN METODE Jenis Penelitian}

Adapun jenis penelitian ini yaitu observasional analitik yaitu penelitian yang dilakukan untuk menghubungkan antara variabel independent dan variabel dependent dengan pendekatan "cross sectional" yaitu penelitian pada beberapa populasi yang diamati pada waktu yang sama.

Variabel dependen pada penelitian ini yaitu indeks prestasi kumulatif dan variabel independen status gizi

\section{Lokasi Penelitian}

Lokasi penelitian dilakukan di kampus Poltekkes Kemenkes Sorong Jurusan D III Kebidanan tingkat II. Penelitian ini dilaksanakan pada bulan Mei 2014.

\section{Sampel}

Pada penelitian ini sampel yang diambil adalah sebagian dari mahasiswi DIII Kebidanan tingkat II yang berjumlah 83 orang.

Pada penelitian ini menggunakan teknik Accidental Sampling dimana sampel yang diambil adalah responden yang kebetulan ada atau tersedia pada saat penelitian dilakukan.

\section{Defenisi Operasional}

Definisi operasional adalah untuk membatasi ruang lingkup atau pengertian dan variabel-variabel yang diteliti atau diamati (Notoatmojo, 2012).

\section{Status Gizi}

Keadaan tubuh mahasiswi D III kebidanan tingkat II sebagai akibat konsumsi makanan dan penggunaan zat-zat gizi. yang diukur berdasarkan Indeks Massa Tubuh (IMT) (The Asia Pasific Perspective : Redefinising Obesity and its Treatment, 2000)

\section{Indeks Prestasi Kumulatif}

Angka yang menunjukkan prestasi mahasiswi Jurusan DIII Kebidanan secara kumulatif mulai dari semester pertama sampai semester akhir (tiga) yang di tempuh. Yang diukur berdasarkan hasil studi (KHS) mahasiswi semester I sampai dengan semester III

\section{Instrumen dan Cara Pengumpulan Data}

Instrumen penelitian yang digunakan dalam penelitian ini adalah format isian yang berisi semua data yang dibutuhkan dalam penelitian yang diisi sendiri oleh Peneliti.

Instrument yang digunakan dalam penelitian ini adalah:

1. Formulir identitas responden.

2. Microtoice dengan ketelitian $0,1 \mathrm{~cm}$, digunakan untuk mengukur tinggi badan responden.

3. Weight scale dengan ketelitian $0,1 \mathrm{~kg}$, digunakan untuk mengukur berat badan responden.

\section{Teknik Pengolahan Data}

Teknik pengolahan data merupakan langkah-langkah yang dilakukan peneliti 
dalam mengolah data yang dikumpulkan dari responden dengan observasi yaitu :

1. Editing atau pemeriksaan data yaitu memberikan kelengkapan kesinambungan dan keseragaman dalam pengisian kusioner atau checklist

2. Pemindahan data yaitu data yang berupa kode dipindahkan dalam suatu media yang mudah diolah.

3. Tabulasi atau penyusunan data yaitu menyusun data dalam bentuk tabel.

\section{Analisis Data}

1. Analisis Univariat

\section{HASIL PENELITIAN}

\section{Gambaran Umum Lokasi Penelitian} Perkembangan pendidikan keperawatan di Kabupaten Sorong dimulai pertama kali pada tahun 1950 yaitu dibukanya HULPVERPLEGER atau yang disingkat dengan Sekolah Kesehatan Tingkat pertama.pada tahun 1955 disusul dengan dibukanya Sekolah Hulp verpleger NGD 5 (lima) tahun dari SD atau setingkat Sekolah jenjang kesehatan Tingkat C.

Kemudian dilanjutkan dengan peresmian Poltekkes Kemenkes Sorong pada tanggal 8 Desember 2011 oleh Kepala BPPSDM Kesehatan Kemenkes RI tepatnya pukul 15.00 WIT di kampus Poltekkes Kemenkes Sorong. Penetapan pendirian Poltekkes Kemenkes Sorong sesuai peraturan Menteri Kesehatan RI, Nomor : 1988/Menkes/Per/IX/2011 tentang perubahan peraturan Menteri Kesehatan Nomor 890/Menkes /Per reskerja Politeknik Kesehatan. Kampus politeknik Kemenkes sorong berada di kota Sorong, Distrik Sorong Timur, Kelurahan Klasaman km 11,5 dengan luas $6563 \mathrm{~m}^{2}$. Adapun batas-batas wilayah kampus Poltekkes Kemenkes Sorong

Jumlah keseluruhan mahasiswa Program Studi DIII Kebidanan adalah 71 mahasiswa. Dari jumlah populasi keseluruhan yang berjumlah 106 mahasiswi

\section{Data Umum}

Data umum merupakan data tentang karakteristik responden dimana responden didalam penelitian ini adalah remaja yang dirangkum dalam
Analisis univariat dilakukan terhadap tiap variabel dari hasil penelitian dengan menggunakan tabel distribusi frekuensi sehingga menghasilkan distribusi dan persentase dari tiap variabel.

2. Analisis Bivariat

Dalam penilitian ini analisa data yang digunakan dengan melakukan uji statistic yaitu uji Chi-kuadrat $\left(\mathrm{X}^{2}\right)$.

beberapa kriteria yaitu karakteristik respoden seperti jumlah responden.

\section{Data Khusus}

a. Analisa univariat

Analisa univariat adalah menganalisa data yang akan diuji yaitu masing-masing variabel independent dan variabel dependent kemudian didistribusikan kedalam tabel distribusi frekuensi. Adapun data khusus sebagai berikut:

1) Distribusi frekuensi Menurut Status Gizi

Tabel 1

Distribusi Responden menurut Status Gizi Mahasiswi Jurusan DIII

Kebidanan Tingkat II Poltekkes Sorong Tahun 2014

\begin{tabular}{|c|c|c|}
\hline \multirow{2}{*}{$\begin{array}{c}\text { Status } \\
\text { Gizi }\end{array}$} & \multicolumn{2}{|c|}{ Jumlah } \\
\cline { 2 - 3 } Lebih & 13 & $\%$ \\
\hline Baik & 47 & 66,2 \\
\hline Kurang & 11 & 15,5 \\
\hline Total & 71 & 100 \\
\hline
\end{tabular}

Sumber :Data Primer Terolah, 2014

Pada Tabel 1 frekuensi tertinggi berada pada status gizi baik sebanyak 47 responden $(66,2 \%)$ dan terendah berada pada status gizi kurang sebanyak 11 responden $(15,5 \%)$.

Tabel 2

Distribusi Responden Menurut Tingkat Prestasi Mahasiswa Jurusan DIII Kebidanan 
Tingkat II Poltekkes Kemenkes Sorong tahun 2014

\begin{tabular}{|c|c|c|}
\hline \multirow{2}{*}{ IPK } & \multicolumn{2}{|c|}{ Jumlah } \\
\cline { 2 - 3 } & $\mathrm{N}$ & $\%$ \\
\hline Tinggi & 67 & 94,4 \\
\hline Kurang & 4 & 5,6 \\
\hline Total & 71 & 100 \\
\hline
\end{tabular}

Sumber :Data Primer, 2014

Pada tabel 2. frekuensi tertinggi berada pada prestasi tinggi sebanyak 67 responden $(94,4 \%)$ dan terendah berada pada prestasi kurang sebanyak 4 responden (5,6\%).

b). Analisis Bivariat

Tabel 3.

Tabulasi Silang Status Gizi Terhadap Indeks Prestasi Kumulatif

Mahasiswi Jurusan DIII Kebidanan Tingkat II

Poltekkes Kemenkes Sorong

\begin{tabular}{|c|c|c|c|c|c|c|c|c|}
\hline \multirow{3}{*}{$\begin{array}{c}\text { Status } \\
\text { Gizi }\end{array}$} & \multicolumn{4}{|c|}{ IPK } & \multirow{2}{*}{\multicolumn{2}{|c|}{ Total }} & \multirow{3}{*}{$\begin{array}{c}X^{2} \\
\text { hit } \\
\text { ung }\end{array}$} & \multirow{3}{*}{$\begin{array}{c}X^{2} \\
\text { tab } \\
\text { el } \\
\end{array}$} \\
\hline & \multicolumn{2}{|c|}{ Tinggi } & \multicolumn{2}{|c|}{ Kurang } & & & & \\
\hline & $\mathrm{n}$ & $\%$ & $\mathrm{n}$ & $\%$ & $\mathrm{n}$ & $\%$ & & \\
\hline Le & 12 & 92,3 & 1 & 7,7 & 13 & 10 & \multirow{4}{*}{$\begin{array}{l}3,9 \\
22\end{array}$} & \multirow{4}{*}{$\begin{array}{l}5,9 \\
91\end{array}$} \\
\hline B & 45 & 95,8 & 2 & 4,2 & 47 & 100 & & \\
\hline $\begin{array}{c}\text { Kuran } \\
\text { g }\end{array}$ & 10 & 90,9 & 1 & 9,1 & 11 & 100 & & \\
\hline Total & 67 & 94,4 & 4 & 5,6 & 71 & 100 & & \\
\hline
\end{tabular}

Sumber: Data primer, 2014

Pada tabel 3. Frekuensi tertinggi berada pada Status Gizi Baik yang memilikiki IPK tinggi ada 45 responden dan yang kurang ada 2 responden, dan frekuensi terendah berada pada status gizi kurang yang memiliki IPK tinggi ada 10 responden dan yang kurang ada 1 responden.

\section{PEMBAHASAN}

Zat gizi adalah ikatan kimia yang di perlukan tubuh untuk melakukan fungsinya, yaitu menghasilkan energi, membangun dan memelihara jaringan, serta mengetur prosesproses kehidupan. Status gizi (Nutrien) adalah keadaan tubuh sebagai akibat konsumsi makanan dan penggunaan zat-zat gizi. Di bedakan antara status gizi kurang, baik, dan lebih. Gizi dikatakan baik apabila terdapat keseimbangan dan keserasian antara pertumbuhan fisik dan perkembangan mental. Gizi kurang terjadi apabila tubuh mengalami kekurangan satu atau lebih zatzat gizi esensial yang menyebabkan terjadinya gangguan belajar (learning disabilities), kemampuan bekerja kurang, kesakitan sampai kematian. Status gizi dipengaruhi oleh faktor external dan faktor internal. Faktor external antara lain:tingkat pendapatan, pendidikan, pekerjaan, dan budaya. Sedang faktor internal yang mempengaruhi status gizi antara lain usia dan kondisi fisik (Almatsier, 2003).

Indeks Prestasi Kumulatif (IPK) merupakan angka yang menunjukkan prestasi atau kemajuan belajar peserta didik secara kumulatif mulai dari semester pertama sampai semester akhir yang di tempuh. Batas minimal IPK adalah 2,00, dengan rumus penghitungan IPK= Jumlah (SKS x Angka Mutu) seluruh semester : Jumlah (SKS) seluruh semester. Untuk mendapatkan nilai huruf mutu tiap mata kuliah menggunakan Nilai absolute (atau nilai murni ataun nilai mutlak) yang dapat di kelompokkan dalam bentuk angka pecahan dengan rentang skor (salah satu) antara 0100 , atau $0,00-4,00$. Nilai ini bersal dari dosen pengajar mata kuliah tunggal atau dari penilaian beberapa dosen pengajar kelompok team teaching, dari nilai kuis, penugasan, UTS, laporan hasil pratikum/kerja lapangan, ujian pratikum/praktik, dan UAS.

Indeks Prestasi Kumulatif dalam penelitian ini adalah merupakan variabel dependent yang diambil dari nilai semester tiga (III) jurusan DIII Kebidanan tingkat II Poltekkes Kemenkes Sorong tahun 2014.

Pada penelitian ini peneliti mengkategorikan Indeks Prestasi Kumulatif mahasiswa menjadi dua kategori yaitu nilai rendah dimana nilai IPK $<2,75$ dan nilai tinggi dimana nilai IPK $>2,75$.

Berdasarkan penelitian diketahui bahwa mahasiswi jurusan D III Kebidanan Poltekkes Kemenkes Sorong dari 71 mahasiswi terdapat Gizi lebih ada 13 responden $(18.3 \%)$, gizi baik ada 47 responden (66.2\%), gizi kurang ada 11 responden (15.5\%). IPK tinggi ada 67 responden (94.4\%) dan IPK kurang 4 responden $(5.6 \%)$.

Berdasarkan tabulasi silang antara status gizi dengan indeks prestasi kumulatif mahasiswa tingkat II Kebidanan Poltekkes Kemenkes Sorong terdapat 12 responden yang berstatus gizi lebih dengan IPK tinggi dan 1 
responden dengan IPK kurang namun status gizi baik. Sebanyak 45 responden memiliki IPK tinggi dengan status gizi baik, dan 2 responden yang memiliki IPK kurang dengan status gizi kurang. Sedangkan sebanyak 10 responden memiliki IPK tinggi dengan status gizi kurang.

Pada hasil uji Chi Square diperoleh nilai $\mathrm{x}^{2}$ hitung $(3,922)<\mathrm{x}^{2}$ tabel $(5,991)$ yang berarti tidak adanya hubungan antara status gizi dengan indeks prestasi kumulatif mahasiswi DIII kebidanan tingkat II Poltekkes Kemenkes Sorong.

Pada penilitian Khairunnisa yang berjudul Hubungan Status Gizi dengan Indeks Prestasi Kumulatif Mahasiswi Kebidanan Gema Nusantara Bekasi tahun 2011 menyatakan ada hubungan antara status gizi dengan IPK Mahasiswi ini didukung oleh kenyataan yang didapat ternyata status gizi mahasiswa akademi kebidanan gema nusantara di kategorikan baik. Dalam hal ini peneliti berpendapat bahwa status gizi mahasiswa yang baik dapat mempengaruhi IPK mahasiswa, hal ini mungkin dikarenakan pola makan mahasiwa menggunakan ketring asrama. Dan IPK mahasiwa akademi kebidanan gema nusantara dikategorikan tinggi, hal ini dikarenakan mahasiswa berada di asrama sehingga belajar dan waktu bermain keluar dapat terkontrol (Khairunnisa 2011).

Sedangkan pada penelitian ini tidak ada hubungan antara Status gizi dengan IPK Mahasiswi, hal ini bisa dikarenakan IPK dalam penelitian ini dinilai pada semester sebelumnya. Selain itu faktor aktivitas yang terlalu padat sehingga berpengaruh terhadap konsentrasi belajar dan kurang aktifnya mengikuti proses perkuliahan sehingga mata kuliah sebagian besar tertinggal.

\section{KETERBATASAN PENELITIAN}

Keterbatasan penelitian memaparkan hal-hal atau variabel yang sebenarnya tercakup di dalam keluasan lingkup penelitian tetapi karena kesulitankesulitan metodologis atau prosedural tertentu sehingga tidak dapat dicakup di dalam penelitian dan kendali peneliti. Keterbatasan dalam penelitian ini yaitu peneliti tidak mengontrol langsung asupan makanan dan aktivitas fisik responden sehingga pengaruh edukasi gizi yang diberikan tidak memberikan efek yang maksimal.

\section{KESIMPULAN}

Kesimpulan yang dapat ditarik dari penelitian ini adalah sebagai berikut :

1. Frekuensi tertinggi untuk status gizi pada mahasiswi kebidanan tingkat II Poltekkes Kemenkes Sorong adalah status gizi baik yaitu 47 responden $(66,2 \%)$ dan frekuensi terendah adalah status gizi kurang yaitu 11 responden $(15,5 \%)$.

2. Frekuensi tertinggi untuk IPK pada mahasiswi kebidanan tingkat II Poltekkes Kemenkes Sorong adalah IPK tinggi yaitu 67 responden $(94,4 \%)$ dan frekuensi terendah adalah IPK kurang yaitu 4 responden $(5,6 \%)$.

3. Tidak ada hubungan antara status gizi dengan indeks prestasi kumulatif mahasiswi DIII Kebidanan Poltekkes kemenkes Sorong tahun 2014.

\section{SARAN}

Disarankan untuk penelitian selanjutnya dapat meneliti hubungan antara variabel-variabel lain seperti pendapatan keluarga, makanan dan asupan makanan dengan responden yang berbeda, dan mengkaji lebih dalam lagi alasan mengapa tidak ada hubungan antara status gizi dengan prestasi belajar.

\section{REFERENSI}

Anonim, 2009. Status gizi dan faktor yang mempengaruhi (Online), (http://anwarsasake.wordpress.com, diakses tanggal 20 Oktober 2013).

Anonim, 2012. Faktor-faktor yang mempengaruhi status gizi, (online), (http//sumbarsehat.com, diakses tanggal 26 Oktober 2013).

Anonim, 2012. Menentukan status gizi dan kebutuhan zat gizi, (online), (http://esgezetpunyablog.blog.blogs pot.com, diakses tanggal 26 oktober 2013). 
Almatsier, Sunita. 2011. Gizi Seimbang Dalam Daur Kehidupan. PT Gramedia Pustaka Utama. Jakarta.

Almatsier, Sunita. 2009. Prinsip Dasar Ilmu Gizi. Gramedia Pustaka Utama. Jakarta.

Arisman. 2009. Gizi Dalam Dan Kehidupan. EGC. Jakarta

Aulia, Rizal. 2011. Gizi dan Kecerdasan,(http://rizasgz2011.blog spot.com/p/gizi-dan-

kecerdasan.html, diakses tanggal 27 Oktober 2013).

Badan PPSDM. 2010. Pedoman Penyusunan Kurikulum, standar Proses Pembelajaran, Standar Perorangan, Standar Penilaiaan. Kementrian RI. Jakarta.

Berg A. (1986). Peranan Gizi dalam Pembangunan Nasional. CV Rajawali. Jakarta.

Depkes RI, 2002. Pedoman Umum Gizi Seimbang. Direktorat Jenderal Bina Kesehatan Masyarakat. Jakarta.

Depkes RI, 2004. Kecenderungan Masalah Gizi Dan Tantangan Di Masa Yang Akan Datang. Jakarta.

Hardinsyah, 2007. Inovasi dan Pengembangan Modal Sosial Bagi Peningkatan

Kualitas Hidup Manusia dan Pengentasan Kemiskinan. Orasi Ilmiah, Fakultas Ekologi Manusia. Institut Pertanian Bogor.

Hastono, SP. 2001. Modul Analisis Data. Depok. Fakultas Kesehatan
Masyarakat Universitas Indonesia. Jakarta.

Isir, W. 2012. Pedoman Penyelenggaran Pendidikan Politeknik Kesehatan Kemenkes Sorong. Poltekkes Sorong. Sorong.

Khairunisa, 2011. Hubungan Status Gizi dengan Indeks Prestasi Kumulatif Mahasiswi Kebidanan. KTI. Bekasi.

Kapisa, Robi. 2013. Gambaran Status Gizi Terhadap Prestasi Akademik Mahasiswa / Mahasiswi Jurusan Keperawatan. KTI.Sorong.

Pujinarti, SA.2007. GAKY Dalam Gizi Dan Kesehatan Masyarakat. Departemen Gizi Dan Kesehatan Masyarakat Mg FKM UI.

Ridwan. 2009. Belajar Mudah Penelitian Untuk Guru - Karyawan Dan Peneliti Pemula. ALFABETA. Bandung.

Soekirman. (2002). Ilmu Gizi dan Aplikasinya. Dirjen Perguruan Tinggi Depdiknas. Jakarta.

Sugiono. 2012. Statistika untuk Penelitian. Alfabeta. Bandung.

Suhardjo. 2003. Berbagai Cara Pendidikan Gizi. Bumi Aksara. Jakarta.

Sunarto. (2012). Gizi seimbang. Diakses dari ((http:/female.kompas. com). (Online). Diakses pada 27 Oktober 2013).

Supariasa, I Dewa Nyoman, dkk. 2002. Penilaiaan Status Gizi. EGC. Jakarta 
